\title{
Functional characterization of a broad and potent neutralizing monoclonal antibody directed against outer membrane protein (OMP) of Salmonella typhimurium
}

\author{
Prakash Narayana Reddy ${ }^{1} \cdot$ Shivakiran Sathyanarayan Makam ${ }^{1}$ (1) $\cdot$ Rohini Krishna Kota ${ }^{1} \cdot$ Gyati Yatung ${ }^{2}$. \\ Radhika Madam Urs ${ }^{2} \cdot$ Harshvardhan Batra ${ }^{2} \cdot$ Urmil Tuteja $^{3}$
}

Received: 9 October 2019 / Revised: 10 January 2020 / Accepted: 19 January 2020 /Published online: 29 January 2020

(C) Springer-Verlag GmbH Germany, part of Springer Nature 2020

\begin{abstract}
In the present study, we have generated a murine monoclonal antibody (mAb) named Sal-06 by using the crude outer membrane protein preparation of Salmonella enteric subsp. enterica serovar Typhimurium ATCC 14028 strain as antigen. Sal-06mAb belonging to IgG1 isotype demonstrated broad cross-reactivity to standard and isolated strains of genus Salmonella and others such as Escherichia coli, Klebsiella pneumonia, and Proteus mirabilis. Cross-reactivity across several bacterial genera indicated that the epitopes reactive to Sal-06mAb are conserved among these members. Neutralizing effects of Sal-06mAb on Salmonella growth and survival was evaluated in vitro using bacteriostatic and bactericidal activity with and without complement and bacterial invasion inhibition assay. Sal-06mAb demonstrated a bacteriostatic effect on the growth of S. typhimurium ATCC 14028 strain which is both time and concentration (of $\mathrm{mAb}$ ) dependent. It was also found that the bacterial growth inhibition was complement independent. When the bacterial cells were preincubated with Sal-06mAb, it reduced the adherence and invasion of bacterial cells into A549 epithelial cell line. This was confirmed by CFU count analysis, phase contrast, and fluorescence microscopy. Scanning electron microscope (SEM) imaging confirmed the antimicrobial effects of Sal-06mAb on S. typhimurium ATCC 14028. The development of broadly reactive and cross protective Sal-06mAb opens new possibilities for immunotherapy of sepsis caused by Gram-negative Enterobacteriaceae members.
\end{abstract}

Keywords Monoclonal antibody $\cdot$ Neutralizing antibody $\cdot$ Cross-reactivity $\cdot$ Enterobacteriaceae $\cdot$ Bacteriostatic $\cdot$ Bactericidal assay

\section{Introduction}

Salmonella is an important genus of the family Enterobacteriaceae and the most common pathogenic bacteria which causes diarrhea, gastroenteritis, typhoid,

Shivakiran Sathyanarayan Makam

shivasaimsk@gmail.com

1 Department of Biotechnology, Vignan's Foundation for Science, Technology and Research (Deemed to be University), Vadlamudi, Guntur district, Andhra Pradesh 522 213, India

2 Department of Microbiology, Defence Food Research Laboratory (DFRL - DRDO), Siddartha Nagar, Mysore, Karnataka 570 011, India

3 Department of Microbiology, Defence Research \& Development Establishment (DRDE - DRDO), Gwalior, Madhya Pradesh 474 002, India paratyphoid fever, septicemia, and other clinical syndromes with varying degrees of severity (Di Febo et al. 2019; Li et al. 2019). Salmonella is commonly found in intestinal tract of humans and animals and therefore presence of Salmonella in food and raw materials is an indication of fecal contamination. Certain non-typhoidal Salmonella strains are responsible for bloodstream infections which are referred to as invasive non-typhoidal Salmonella (INTS) infections. The Global Burden of Diseases, Injuries, and Risk Factors Study (GBD) published that Salmonella enterocolitis resulted in $\sim 95.1$ million cases and 50,771 deaths in 2017. The symptoms are not typical of diarrhea and present as febrile illness with higher fatality rate (Stanaway et al. 2019). The disease burden is disproportionate affecting adults or children with weak immune system. Intervention and control of the infection depends on rapid detection of these pathogens followed by appropriate therapeutic interventions. 
Antimicrobial resistance to several classes of antibiotics such as penicillins, tetracyclines, fluoroquinolones, sulfonamides, aminoglycosides, and cephalosporins is another major concern in treatment of Salmonella infections (Lamas et al. 2018). Passive immunization has been successfully used as an alternate method of prophylaxis against several gastrointestinal pathogens such as Campylobacter, Salmonella, E. coli, rotavirus, and coronavirus (Esmailnejad et al. 2019). Interest towards antibody-based therapy was prompted based on the need to find suitable alternatives to conventional antibiotics in view of a widespread antimicrobial resistance.

Selection of right virulence factors as target for therapeutic intervention plays a key role in disease control. Several studies have shown that outer membrane proteins (OMPs) of bacteria are strong immunogenic components and possible vaccine candidates (Babu et al. 2017; Abadi et al. 2018; Neema and Karunasagar 2008). Outer membrane proteins include integral membrane proteins as well as lipoproteins that are anchored to the outer membrane via $\mathrm{N}$ terminally attached lipid. Generally, OMPs are characterized by $\beta$-barrel structures and integral OMPs are essential for maintaining the integrity and selective permeability of bacterial membranes (Lin et al. 2002). Some of them serve as adhesins and play an important role in virulence (Ebanks et al. 2005; Khushiramani et al. 2008). Outer membrane proteins are extremely immunogenic ( $\mathrm{Li}$ et al. 2014) and therefore they would be effective candidates for vaccine and diagnostic development owing to their exposed epitopes on the cell surface. The OMPs of Salmonella are also known to have a significant role in eliciting immune response (Meenakshi et al. 1999). They have been considered potential candidates for conferring protection against typhoid. Salmonella OMPs have been investigated as potential vaccine candidates, virulence factors, and diagnostic antigens (Isibasi et al. 1988). Therefore, generation of antibodies specific against surface and structural components might prevent establishment of infection.

In the present study, we utilized the $S$. typhimurium OMP preparation as antigen of choice to develop mAbs reactive against the members of the genus Salmonella. One monoclonal antibody namely Sal-06 was functionally characterized by several in vitro assays to study the effectiveness of $\mathrm{mAb}$ in fighting the Salmonella infections. A preliminary attempt was made to understand the ability of $\mathrm{mAb}$ to block the pathogen before undertaking in vivo challenge studies. The cross-reactivity, antibacterial and invasion inhibition assays were performed to examine the anti-Salmonella properties of Sal-06 monoclonal antibody.

\section{Materials and methods}

\section{Materials}

\section{Bacterial cultures and cell lines}

The bacterial strains used in the present study are S. typhimurium ATCC 14028, S. paratyphi MTCC 735, S. typhi Typhi isolate Gwalior, S. bovismorbificans MTCC 1162, S. infantis MTCC 1167, S. newporti isolate, S. typhimurium NCIM 5278, S. enteritidis isolate Gwalior, Klebsiella pneumoniae ATCC 13883, Proteus mirabilis MTCC 3310, Citrobacter freundii ATCC 8090, Shigella flexneri ATCC 9199, Enterobacter aerogenes ATCC 13048, and Escherichia coli ATCC 10536. A549 epithelial cell line was used in the present study. Cell line A549 was purchased from National Centre for Cell Sciences (NCCS), Pune, India. A549 cell line is derived from adenocarcinomic human alveolar basal epithelial cell.

\section{Media components, chemicals, and reagents}

Dehydrated media such as brain heart infusion broth and Mueller-Hinton broth for bacterial propagation were procured from HiMedia laboratories, Mumbai, India. Cell culture media, reagents, and antibiotics were procured from SigmaAldrich, India. Inorganic salts and organic solvents were from Sisco Research Labs, India. BHI broth or agar was used for culturing, propagation, and storing of all bacterial strains. Mueller-Hinton media was used for bacteriostatic/ bactericidal assays and invasion-inhibition assays. All bacterial cultures used in this study were grown at $37{ }^{\circ} \mathrm{C}$ under constant agitation of 200 RPM. A549 cell line was propagated in Dulbecco Modified Eagle's medium (DMEM) supplemented with $10 \%$ fetal bovine serum (FBS) with appropriate antibiotics and maintained at $37{ }^{\circ} \mathrm{C}$ under $5 \% \mathrm{CO}_{2}$.

\section{Outer membrane protein preparation}

Crude OMP was prepared from overnight culture of S. typhimurium ATCC 14028 as described by Arora et al. (2006). Briefly, S. typhimurium was grown in Brain Heart infusion broth overnight followed by harvesting the cells by centrifugation at $4{ }^{\circ} \mathrm{C}$. The cells were washed in PBS twice and dissolved in $30 \mathrm{ml}$ of $10 \mathrm{mM}$ Tris containing $0.3 \% \mathrm{NaCl}$. The cells were subjected to sonication (Vibra-Cell sonicator, Sonics \& Materials Inc., Newtown, CT), at amplitude $10 \mu \mathrm{m}$ in ice for $10 \mathrm{~s}$ of six repetitions with 20 -s intervals. The lysate was subjected to centrifugation for $2 \mathrm{~min}$ at $7000 \mathrm{~g}$ followed by centrifugation of supernatant at $14,000 \mathrm{~g}$ for $1 \mathrm{~h}$ at $4{ }^{\circ} \mathrm{C}$. The pellet was suspended in $10 \mathrm{mM}$ Tris containing $3 \%$ sodium lauryl sarcosinate (sarkosyl) and incubated overnight at 
$4{ }^{\circ} \mathrm{C}$. Crude OMP extract was obtained by centrifugation at $14,000 \mathrm{~g}$ at $4{ }^{\circ} \mathrm{C}$. OMPs were washed in distilled water and dissolved in $1 \times \mathrm{PBS}$ and stored at $-20^{\circ} \mathrm{C}$ for further use. The protein concentration was determined by Lowry's colorimetric assay.

\section{Generation and characterization of Sal-06 monoclonal antibody}

\section{Hybridoma procedure}

Outer membrane protein preparation extracted from strain S. typhimurium ATCC 14028 was used for immunizing 5-6week-old female BALB/c mice. Mice were maintained in 12$\mathrm{h}$ light and dark cycles alternately. Mice were provided with food pellets from a commercial vendor. Mineral water from Kent water purifier was given to mice during the study period. Rice hulls were used as bedding material and changed every 2 or 3 days. Two female mice were housed in each polypropylene enclosure. Fifty microgram quantity of OMP was administered subcutaneously in emulsion with Freund's complete adjuvant followed by two booster doses with the same quantity of protein in emulsion with Freund's incomplete adjuvant at 15-day interval. Antibody titers were determined by indirect ELISA using extracted OMP preparation as antigen. After sufficient titers were reached, mice were sacrificed, spleens were aseptically dissected, and the collected splenocytes were fused with mouse myeloma cell line SP2/O Ag-14 by PEGylation method. The fused cells were propagated in HAT medium and the hybrids were screened for reactivity with OMP preparation. One mAb named Sal-06 showing strong reactivity was separated and used for further studies. Sal-06mAb was purified by growing Sal-06 clone in DMEM supplemented with $10 \%$ FBS in $75 \mathrm{~cm}^{2}$ culture flasks until $75 \%$ confluency. The cells are transferred to serum-free media and grown for another 2-3 days. The cell-free culture supernatant was separated and used for purifying Sal-06mAb.

\section{Ammonium sulfate precipitation and dialysis}

Cell culture supernatant (CCS) collected from Sal-06 clone was subjected to centrifugation at $1100 \mathrm{~g}$ for $10 \mathrm{~min}$ to remove cells. The supernatant $(100 \mathrm{ml})$ was treated by ammonium sulfate precipitation for concentration and recovery of mAbs. Briefly, to the CCS, $1 / 10^{\text {th }}$ volume $1 \mathrm{M}$ Tris-Cl ( $\mathrm{pH} 8.0$ ) was added and mixed. To this mixture, $100 \%$ ammonium sulfate solution was added dropwise under continuous stirring until the mixture turned turbid (required about $\sim 30 \mathrm{ml}$ ). The mixture was incubated at $4{ }^{\circ} \mathrm{C}$ for $2 \mathrm{~h}$. The solution was subjected to centrifugation at $6000 \mathrm{~g}$ at $4^{\circ} \mathrm{C}$ for $1 \mathrm{~h}$. To the pellet, $5 \mathrm{ml}$ of $100 \%$ ammonium sulfate solution was added, mixed, and again subjected to centrifugation at $6000 \mathrm{~g}$ at $4{ }^{\circ} \mathrm{C}$ for
$30 \mathrm{~min}$. The pellet was dissolved in $2.0 \mathrm{ml}$ of $1 \times$ PBS and the excess salt was removed by dialysis against 1000 volumes of $1 \times$ PBS solution overnight. The buffer was changed at least three during dialysis before collecting the concentrated $\mathrm{mAb}$ from Sal-06 clone. Finally, the Sal-06mAb was purified to homogeneity using protein A chromatography kit (SigmaAldrich, India). Isotype of Sal-06mAb was determined by Isoquick mouse monoclonal antibody isotyping kit (SigmaAldrich, India).

\section{Lyophilization}

Concentrated Sal-06mAb was divided into aliquots and subjected to lyophilization for future use. Briefly, aliquots were frozen in $-80{ }^{\circ} \mathrm{C}$ and the frozen samples were placed in a lyophilizer (Lyodel - Delvac pumps, India) precooled to $55{ }^{\circ} \mathrm{C}$ and subjected to lyophilization at $1.2 \mathrm{psi}$ for $4 \mathrm{~h}$. The lyophilized samples were stored in $-20{ }^{\circ} \mathrm{C}$ until further use. The completely dried samples were dissolved in sterile distilled water when required and passed through $0.22-\mu \mathrm{m}$ sterile syringe filter (Pall Life Sciences, India). The antibody concentration was quantified by Lowry's colorimetric assay using $\mathrm{BSA}$ as standard. The concentration of the mAb was adjusted to $\sim 2 \mathrm{mg} / \mathrm{ml}$.

\section{SDS-PAGE and western blot analysis}

SDS-PAGE and western blot analysis were carried out to check the reactivity of Sal-06mAb with different bacterial strains belonging to Enterobacteriaceae. Briefly, SDS-PAGE was performed using Bio-Rad Mini-PROTEAN Tetra Cell apparatus as per the procedure of Laemmli (1970) with minor modifications. One milliliter of overnight bacterial cells was harvested by centrifugation and dissolved in equal volumes of $1 \times$ PBS and $2 \times$ Laemmli buffer. The bacterial samples were subjected to boiling for $10 \mathrm{~min}$ followed by centrifugation at $13,500 \mathrm{~g}$ for $5 \mathrm{~min}$ to separate cell debris. Ten microliters of cell lysate supernatant was loaded on $12 \%$ SDS-PAGE gels and resolved at $100 \mathrm{~V}$. Separated proteins on resolved gels were transferred to charged nitrocellulose membrane ( $0.45 \mu \mathrm{m}$, Pall Life Sciences) by electroblotting by wet transfer in Bio-Rad Mini Trans-Blot cell at $70 \mathrm{~V}$ for $60 \mathrm{~min}$. After blotting, membranes were blocked in 5\% skim milk solution overnight at $4{ }^{\circ} \mathrm{C}$. Excess milk protein was washed in PBST (Tween 20,0.05\%) solution. Next, the membrane was incubated in 1:2000 dilutions of Sal-06mAb at room temperature on a gel rocker. The membrane was washed in PBST and incubated with goat anti-mouse IgG conjugated with HRP (1:5000 dilutions). After washing the membrane with PBST, the blots were developed using diaminobenzidine tetrahydrochloride hydrate and $0.003 \% \mathrm{H}_{2} \mathrm{O}_{2}$ solution in PBS. 


\section{Dot ELISA}

Overnight cultures were used for dot ELISA. Five hundred microliter volume of culture was harvested by centrifugation followed by dissolving the bacterial cells in equal volumes of carbonate-bicarbonate buffer ( $\mathrm{pH}$ 9.2). Ten microliters of the cells was coated onto grids of $1 \times 1 \mathrm{~cm}$ on nitrocellulose (NC) strip and air dried for $10 \mathrm{~min}$. NC strips were blocked in 5\% milk solution for $1 \mathrm{~h}$ at room temperature. Strips were washed in PBST solution 4-5 times and incubated in diluted Sal$06 \mathrm{mAb}$. After washing, membrane was incubated with goat anti-primary antibody conjugated to HRP. Membranes were further washed in PBST and developed with diaminobenzidine (DAB) tetrahydrochloride (Sigma-Aldrich, India) solution and $0.003 \% \mathrm{H}_{2} \mathrm{O}_{2}$ in PBS.

\section{Bacteriostatic/bactericidal studies of Sal-06mAbSal-06mAb}

The effect of Sal-06mAb on the survival and growth of S. typhimurium ATCC 14028 was evaluated by bacteriostatic/bactericidal assays using microtiter plates. S. typhimurium ATCC 14028 strain was grown overnight in Mueller-Hinton broth (MHB). The culture was diluted to $10^{5} \mathrm{CFU} / \mathrm{ml}$ in MHB. Lyophilized Sal-06mAbSal-06mAb was reconstituted in sterile distilled water and adjusted the concentration to $1 \mathrm{mg} / \mathrm{ml}$. The $\mathrm{mAb}$ was added to Salmonella culture at various concentrations such as 120 , 60 , and $30 \mu \mathrm{g}$. The mAb was added to MHB $(100 \mu \mathrm{l})$ and mixed with $100 \mu \mathrm{l}$ of $S$. typhimurium ATCC 14028 diluted in the above step in triplicates in 96-well microtiter plate with lid. As control, sterile MHB with no mAb and $100 \mu \mathrm{l}$ of bacterial cells were used. To understand if the mAb would nonspecifically bind to other bacteria and inhibit the growth, we also mixed Enterobacter aerogenes ATCC 13048 in triplicates with $120 \mu \mathrm{g}$ of mAb. Wells with $200 \mu \mathrm{l}$ of sterile MHB were used as blank. The plate was incubated at $37^{\circ} \mathrm{C}$ with constant shaking at 200 RPM in Tecan Multimode reader (M200Pro) and the absorbance was read at $595 \mathrm{~nm}$ every hour for $14 \mathrm{~h}$.

\section{Effect of complement on bactericidal activity}

The effect of complement on bactericidal activity was studied by adding mouse complement from serum. The blood was collected from unimmunized mice by retro-orbital puncturing. The blood was incubated at $37{ }^{\circ} \mathrm{C}$ for $1 \mathrm{~h}$ and followed by centrifugation at $2348 \mathrm{~g}$ for $5 \mathrm{~min}$ to separate the serum. The serum was collected and stored at $-20{ }^{\circ} \mathrm{C}$ until further use. The complement assay was performed similar to bacteriostatic assay except that $10 \mu \mathrm{l}$ of serum which contained complement was added to each well along with $\mathrm{mAb}$, MHB, and S. typhimurium ATCC 14028 cells as described in the methods section "Bacteriostatic/bactericidal studies of Sal-06mAb."
The microtiter plate was covered and kept under shaking at $175 \mathrm{RPM}$ for $14 \mathrm{~h}$ and the absorbance was read at $595 \mathrm{~nm}$ every $1 \mathrm{~h}$.

\section{Invasion inhibition assay}

Invasion inhibition assay was performed on A549, a human alveolar epithelial cell line. The cells were grown in tissue culture flask to $80-90 \%$ confluence in DMEM with $10 \%$ FBS and suitable antibiotics at $37^{\circ} \mathrm{C}$ with $5 \% \mathrm{CO}_{2}$. Cells were dislodged by $0.025 \%$ trypsin treatment. The cells were centrifuged at $300 \mathrm{~g}$ at room temperature for $5 \mathrm{~min}$. The cell pellet was resuspended in fresh DMEM with $10 \%$ FBS and transferred to 24 -well plates and incubated at $37^{\circ} \mathrm{C}$ overnight. The following day, the culture supernatant was removed from the A549 cells and washed with sterile $1 \times$ PBS two times. At the same time, the bacterial cells from overnight culture were harvested and washed in PBS, and cells were diluted to $1 \times$ $10^{5} \mathrm{CFU} / \mathrm{ml}$ in DMEM with $10 \%$ FBS. Similarly, mAb was diluted to $100 \mu \mathrm{g} / \mathrm{ml}$ in DMEM with $10 \%$ FBS. Now, equal volumes $(300 \mu \mathrm{l})$ of bacterial culture and $\mathrm{mAb}$ were mixed in a single sterile micro centrifuged tube and incubated at $37^{\circ} \mathrm{C}$ for $30 \mathrm{~min}$. As control, only bacterial cells without $\mathrm{mAb}$ were used. This mixture was added along with an equal amount of DMEM media supplemented with $10 \%$ FBS to A549 cells. The plate was incubated in $\mathrm{CO}_{2}$ incubator at $37{ }^{\circ} \mathrm{C}$ and $5 \%$ $\mathrm{CO}_{2}$ for $1 \mathrm{~h}$. After incubation, the media was removed and washed with sterile $1 \times$ PBS twice. Two hundred microliters of fresh DMEM media containing gentamicin was added and incubated at $37^{\circ} \mathrm{C}$ for $30 \mathrm{~min}$. The media was removed, and cells were washed with sterile $1 \times$ PBS twice. A549 cells were lysed with $100 \mu \mathrm{l}$ of $1 \%$ triton X-100. Cells were observed under microscope for confirmation of lysis. To the lysed cells, $900 \mu \mathrm{l}$ of sterile PBS was added, mixed, and collected aseptically in sterile micro centrifuge tubes. One hundred microliters of above culture suspension was subjected to pour plating on plate count agar along with appropriate controls. The plates were incubated at $37^{\circ} \mathrm{C}$ for $24 \mathrm{~h}$ and colonies were counted.

\section{Microscopy studies}

A549 cells were seeded as described in the methods section "Invasion inhibition assay" into 12 -well plates containing gelatin-coated glass cover slips. The cells were incubated at $37^{\circ} \mathrm{C}$ for $12 \mathrm{~h}$ in $5 \% \mathrm{CO}_{2}$. Then, they were washed with sterile $1 \times$ PBS or DMEM media. The mixture of $S$. typhimurium ATCC 14028 culture and $\mathrm{mAb}$ as described in the methods section "Invasion inhibition assay" was added to the 2 wells as duplicates and S. typhimurium ATCC 14028 cells was added without $\mathrm{mAb}$ as control. The bacterial cells were allowed to adhere for $2 \mathrm{~h}$ at $37^{\circ} \mathrm{C}$ in $5 \% \mathrm{CO}_{2}$. Unattached bacterial cells were removed by washing 5-6 times with $1 \mathrm{ml}$ pre-warmed sterile $1 \times$ PBS. Five hundred microliters of diluted FITC 
secondary conjugate was added to each well and kept for $2 \mathrm{~h}$ at room temperature in a dark place. Again, the wells were washed with sterile $1 \times$ PBS several times. The cells on the coverslips were fixed by dipping them in $4 \%$ formalin and then dried for observation under phase contrast and fluorescent microscope.

\section{Scanning electron microscopy}

The effect of mAb on live Salmonella cells' morphology was observed by a scanning electron microscope (FEI, model no.: Quanta 200) analysis. Briefly, S. typhimurium ATCC 14028 was grown overnight in BHI broth. Bacterial cells were washed in filter-sterilized PBS and adjusted the cell count to $10^{6} \mathrm{CFU} / \mathrm{ml}$. Hundred microliters of cells were mixed with $50 \mu \mathrm{g}$ of $\mathrm{mAb}$ and incubated at $37^{\circ} \mathrm{C}$ for $1 \mathrm{~h}$. Bacterial cells without $\mathrm{mAb}$ addition were used as controls. Monoclonal antibody treated and untreated bacterial cells were fixed on conducting dual side carbon tape and coated with gold using a sputter coater (Emitech, model no.: SC7620) and dried out in $\mathrm{CO}_{2}$ chamber. The changes in surface morphological structure of bacterial cells were captured in an environmental mode under SEM at a magnification of $\times 10,000$.

\section{Statistical analysis}

All the statistical analyses were performed using Microsoft Excel 2007. All the ELISA experiments were done in triplicates and the data was represented as Mean \pm SD. Statistical difference between different groups was analyzed using univariate ANOVA and the differences at $p<0.05$ were considered to be significant.

\section{Results}

\section{Outer membrane protein preparation and immunization}

Separation of membrane proteins was achieved using sarkosyl. This method was found to be optimal in recovering of OMPs from membranes (Ghatak et al. 2003). Separation of extracted OMPs showed several bands on Coomassie brilliant blue-stained SDS-PAGE gels ranging from 15 to $70 \mathrm{kDa}$ (Fig. 1). The OMP concentration was found to be $\sim 2.5 \mathrm{mg} / \mathrm{ml}$ by Lowry's assay. The concentration was adjusted to $1 \mathrm{mg} / \mathrm{ml}$ using PBS as diluent. Outer membrane proteins were directly administered as antigen in mice. Antibody titer increased progressively with each booster dose with crude OMP preparation. A primary dose followed by two booster doses was administered until the antibody titers in serum reached 1:64,000 dilutions. The high antibody titer indicated the strong

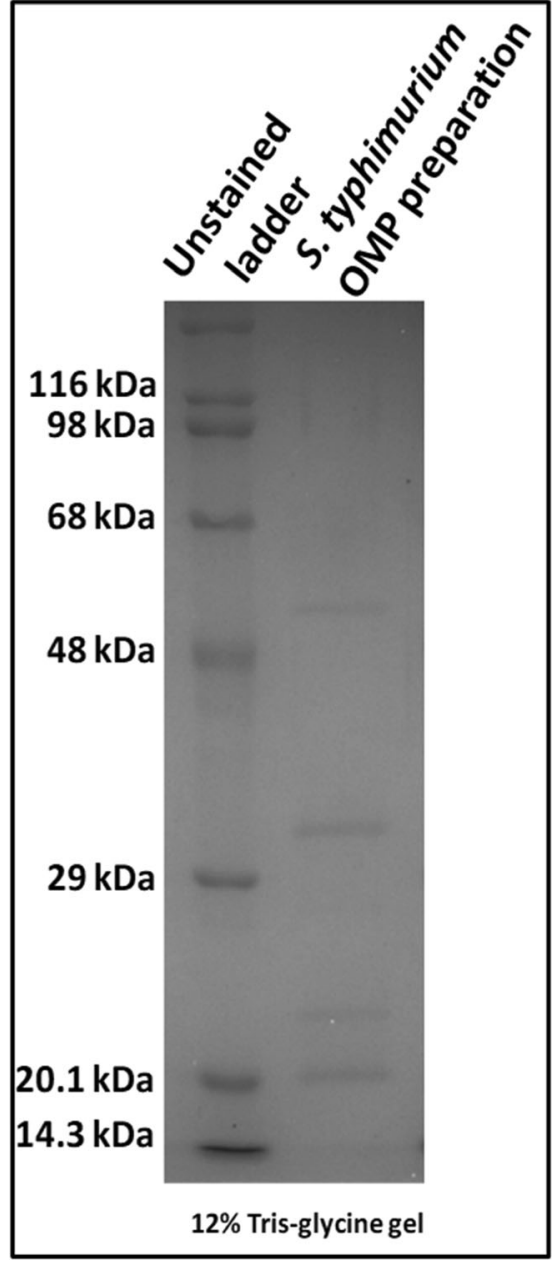

Fig. 1 Coomassie-stained SDS-PAGE gel showing protein profile of crude outer membrane protein prepared from $S$. typhimurium ATCC 14028 strain

immunogenic nature of the OMP preparation. Serum antibodies from the unimmunized mice showed no reactivity with crude OMP. The polyclonal antibodies from serum reacted with both whole $S$. typhimurium cells by dot ELISA (Fig. 2A) while serum from normal mice did not show any reactivity (Fig. 2B).

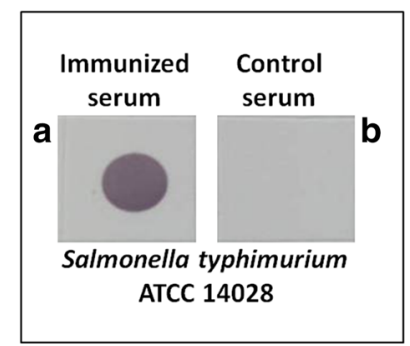

Fig. 2 Dot ELISA performed for testing reactivity of mouse polyclonal anti-Salmonella OMP antibodies with S. typhimurium whole cells. Panel (a) shows reactivity of immune serum with Salmonella cells. Panel (b) shows no reactivity of unimmunized serum with whole cells 


\section{Hybridoma generation}

Five monoclonal antibody clones exhibited reactivity with S. typhimurium OMP preparation after testing the cell supernatants by indirect ELISA in 96-well microtiter plate. Of the five hybridomas, the reactivity of one mAb named Sal-06 was particularly striking. This clone was expanded further and tested for its reactivity with several whole cells and whole cell lysates of S. typhimurium in dot ELISA and western blot analysis respectively. The mAb showed reactivity with all the tested standard and isolated $S$. typhimurium strains in dot ELISA (Fig. 3A) and showed distinct reactivity at $\sim 60 \mathrm{kDa}$ region in western blot analysis (Fig. 3B).

\section{Characterization of Sal-06mAb}

The properties of Sal- $06 \mathrm{mAb}$ were characterized by assessing its isotype, reactivity with different Salmonella species, and closely related members of Salmonella. Isotype analysis revealed that Sal-06mAb clone belongs to IgG1 subclass. Antibody precipitation and concentration procedures did not affect the reactivity of the monoclonal antibody. Sal- $06 \mathrm{mAb}$ displayed reactivity to all the tested Salmonella species such as $S$. typhimurium, S. typhi, S. infantis, S. enteritidis, S. newportii, S. bovismorbificans, and S. paratyphi in western blot analysis (Fig. 4). Due to the conserved nature of epitopes, we are of opinion that the antigen reacting with $\mathrm{mAb}$ might be outer membrane protein (OMP) present in all Salmonella serovars. The reactivity was seen as distinct protein bands in developed blots at $\sim 60 \mathrm{kDa}$ regions. Reactivity of Sal- $06 \mathrm{mAb}$ was tested with non-Salmonella members such as Escherichia coli, Shigella spp. Klebsiella pneumoniae, Proteus spp., and Enterobacter aerogenes. The mAb was found to react with E. coli and Proteus spp. (Fig. 5). The bands for these organisms were also found at $60 \mathrm{kDa}$ except for $E$. coli where it was

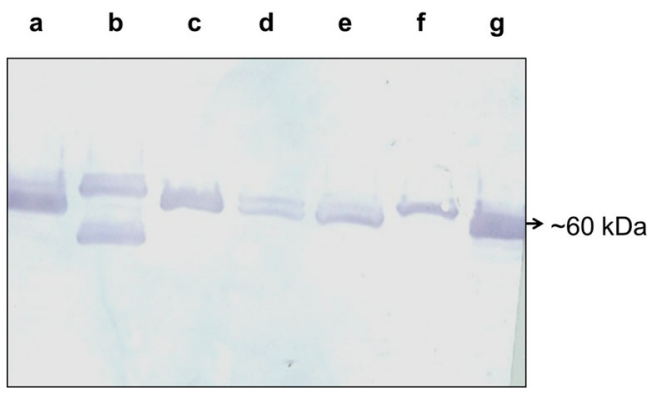

Fig. 4 Reactivity of Sal-06mAb with different species of the genus Salmonella tested by western blot analysis. All the tested species showed reactivity with Sal-06mAb indicating a conserved epitope among these members. (a) S. typhimurium ATCC 14028. (b) S. typhi Gwalior. (c) S. infantis MTCC 1167. (d) S. enteritidis isolate Gwalior. (e) S. newporti isolate. (f) S. bovismorbificans MTCC 1162. (g) S. paratyphi MTCC 735

found to be less than $60 \mathrm{kDa}$. By western blot patterns, we observed that Salmonella shares some common antigens on their outer membrane with other members of Enterobacteriaceae.

\section{Anti-microbial studies of Sal-06mAb}

Since the Sal-06mAb was found to be reactive with OMP of different Salmonella serovars, we investigated if the $\mathrm{mAb}$ possess bacteriostatic/ bactericidal properties. We utilized the standard S. typhimurium ATCC 14028 strain for testing the antimicrobial activity. A standard dilution of $10^{4} \mathrm{CFU} /$ well in $\mathrm{MH}$ broth with different dilutions of $\mathrm{mAbs}$ was incubated for $18 \mathrm{~h}$. We found that $\mathrm{mAb}$ was able to control the growth of the bacteria temporarily. There was visible growth in all the wells; however, differences in the optical density were very clear with varying concentrations of the mAb. Figure 6 depicts a clear distinction of growth curves of the bacteria under various concentrations of $\mathrm{mAb}$. At the highest concentration of $\mathrm{mAb}$,

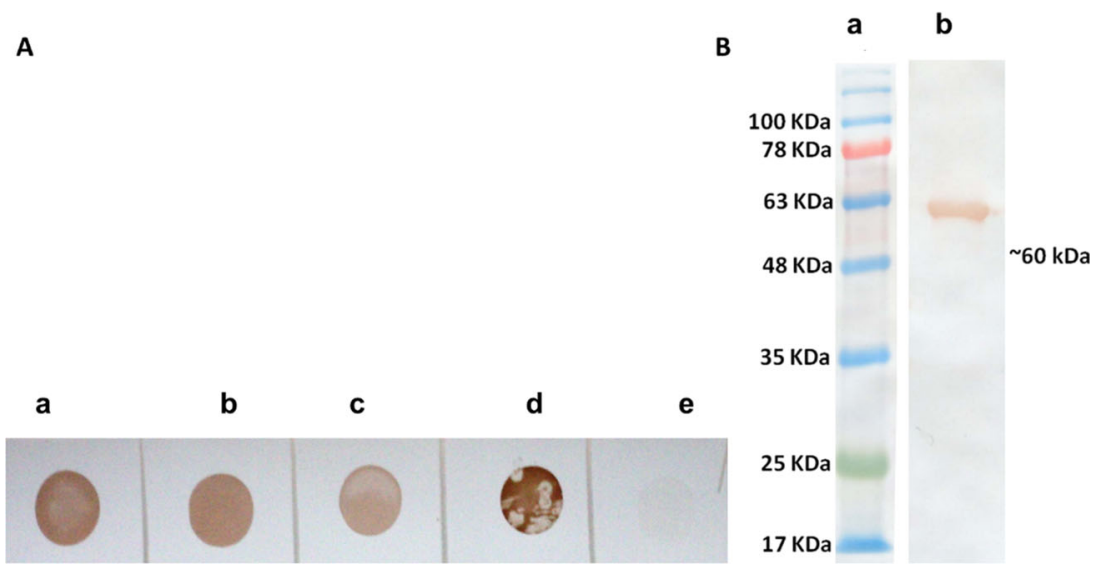

Fig. 3 Reactivity testing of Sal-06mAb by dot ELISA. Dot ELISA was performed with whole cells of different members of the genus Salmonella. Panel A: (a) S. typhimurium ATCC 14028. (b) Salmonella typhi Gwalior isolate. (c) Salmonella paratyphi MTCC 735. (d) Crude
OMP extract. (e) Blank. Western blot analysis. Western blot was performed with whole cell lysate of $S$. typhimurium ATCC 14028 strain. Panel B: (a) Premix protein marker. (b) Salmonella OMP extract 1 
a

b

\section{d}

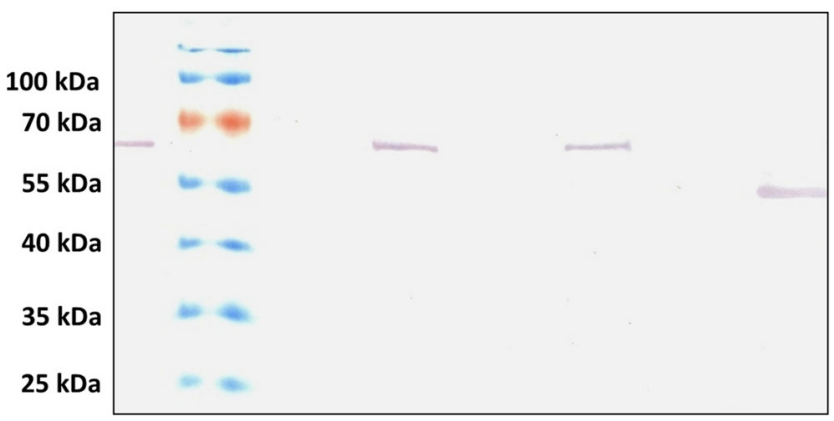

Fig. 5 Reactivity of Sal-06mAb was tested with different members of the family Enterobacteriaceae by western blot analysis. Proteus mirabilis and E. coli showed reactivity with Sal- $06 \mathrm{mAb}$ indicating a conserved epitope among these members. (a) S. typhimurium ATCC 14028. (b) Prestained protein marker. (c) Shigella flexneri NCIM 5265. (d) S. typhimurium NCIM 5278. (e) Klebsiella pneumoniae ATCC 13883. (f) Proteus mirabilis MTCC 3310. (g) Enterobacter aerogenes ATCC 13048. (h) E. coli ATCC 10536

the growth of the bacteria has reduced considerably. In other words, the growth is inhibited but not completely stopped. The growth has resumed after $\sim 6 \mathrm{~h}$ of inoculation, where as in control wells with bacteria and no mAb, the growth resumed immediately. As we decreased the mAb concentration, the time lapse between the control wells and mAb-treated wells was decreasing. To confirm the specificity of inhibitory effect Sal-06mAb to Salmonella, Salmonella cells were treated with $120 \mu \mathrm{g}$ of a control mAb (mouse monoclonal antihistidine antibody - Sigma Aldrich) which did not affect the growth of bacteria from that of untreated control. Therefore, we concluded that the inhibitory effect of $\mathrm{mAb}$ was time and concentration dependent. Also, the growth of the bacteria was inhibited for $4-6 \mathrm{~h}$ but not indefinitely indicating that the effect is bacteriostatic.

\section{Effect on complement on antimicrobial activity}

Complement is part of innate immune system but can be brought in to work by adaptive (humoral) immune system.

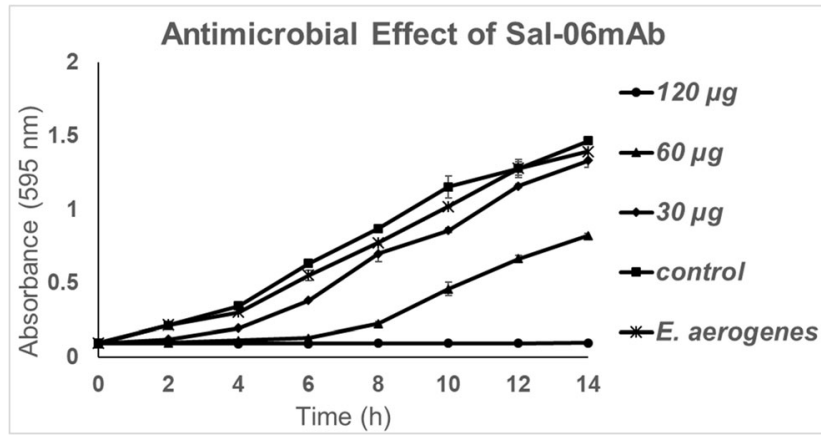

Fig. 6 Bacteriostatic/bactericidal potential of Sal-06mAb was tested by microtiter-based anti-microbial assay. The Sal- $06 \mathrm{mAb}$ exhibited bacteriostatic property at $120 \mu \mathrm{g}$ concentration. The antibacterial activity is both concentration and time dependent
Complement enhances the activity of antibodies and phagocytic cells to clear pathogens, promotes inflammation, and attacks the pathogens' cell membrane. Therefore, we investigated whether the bacteriostatic effect of $\mathrm{mAb}$ was complement dependent. We collected the mouse serum containing the complement and used directly. We conducted the growth curve assay as mentioned above along with complement added to each well. Figure 7 shows the effects of mouse complement system on bacteriostatic effects of mAb. It was revealed that there was no improvement in the reduction of growth in the wells containing complement.

\section{Invasion inhibition assay}

Adherence to intestinal epithelial cells is the first step in invasion process of the intestinal pathogen. We investigated whether the $\mathrm{mAb}$ in the present study would inhibit the pathogen from invading the host cells. One batch of cell lines (epithelial cell line A549) was grown in tissue culture plates for CFU count analysis and another batch was grown on cover slips for microscopy. After incubation with cell lines with and without $\mathrm{mAb}$, the adherent bacterial cells were washed with antibiotics. The bacterial cells invaded into the host cell lines were enumerated after lysis. Simultaneously, the invasion was observed by fluorescent microscope. We found that the bacterial cells were found to invade in the absence of mAbs. The presence of $\mathrm{mAb}$ inhibited Salmonella invasion which can be observed in Table 1 that the bacterial cells preincubated with $\mathrm{mAbs}$ at bacteriostatic concentrations failed to invade the cells; hence, there were no colonies observed after the cell lines were lysed and plated on plate count agar (Table 1).

We also observed the invasion of bacterial cells under phase contrast and fluorescent microscope. We found that the cells incubated with pathogen alone were having damaged cell membranes (Fig. 8B, D). It was observed that the A549

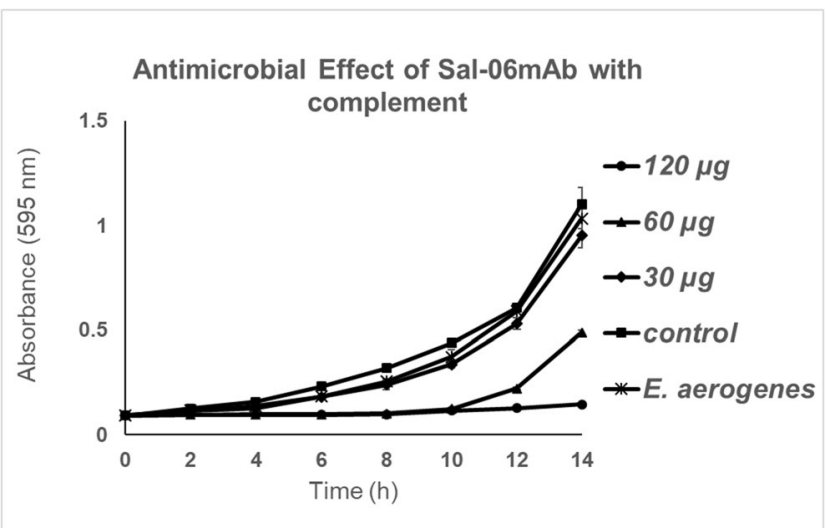

Fig. 7 Bacteriostatic/bactericidal potential of Sal- $06 \mathrm{mAb}$ was tested in the presence of mouse complement by microtiter-based anti-microbial assay. The presence of serum complement did not improve the bacteriostatic property 
Table 1 Colony count of invasion inhibition assay. Number of bacteria invaded A549 cell lines when treated with Sal-06mAb

\begin{tabular}{ll}
\hline Sal-06mAb concentration & Number of colonies (CFU) \\
\hline $120 \mu \mathrm{g}$ & 0 \\
$60 \mu \mathrm{g}$ & 0 \\
$30 \mu \mathrm{g}$ & 28 \\
Control & $1.2 \times 10^{3}$ \\
\hline
\end{tabular}

cells had leaked their cytoplasmic content due to the cellular damage made by the pathogenic bacteria. In contrast, the cell lines were intact when they were invaded by the pathogen preincubated with the mAb (Fig. 8A, C).

\section{SEM analysis}

The mAb-treated Salmonella exhibited distinct morphological alterations in comparison with untreated bacterial cells. Control cells were intact, homogenous, and turgid with smooth membrane (Fig. 9A). Monoclonal antibody-treated Salmonella cells showed severe morphological alterations such as flaccid/squashed cells with uneven wrinkles, protuberances and craters, and collapsed membrane with disrupted cell contents (Fig. 9B). Addition of mouse complement did not favor these morphological damages at bacteriostatic concentrations of monoclonal antibody. Increasing the incubation time promoted damage of cell membranes by mAb (Fig. $9 \mathrm{C})$. From this, we inferred that $\mathrm{Sal}-06 \mathrm{mAb}$ was able to bind outer membrane proteins and was disrupting the integrity of cell membrane.

\section{Discussion}

Globally, Salmonella is the predominant cause of typhoidal and non-typhoidal gastroenteritis infections leading to significant mortality and morbidity (Liu et al. 2018). Non-typhoidal Salmonella alone causes $\sim 93$ million cases of gastroenteritis worldwide annually (Eng et al. 2015). Emergence of multidrug-resistant strains has limited the antibiotic treatment options. Vaccines present an attractive approach to control and prevent Salmonella-associated diseases. Several of the reported vaccines are only experimental or are presently under development. Reports from animal and human studies support the possibility of a safe and effective vaccine against invasive non-typhoidal Salmonella. Studies from animal models demonstrated the efficacy with $\mathrm{O}$-antigens, flagellin proteins, and
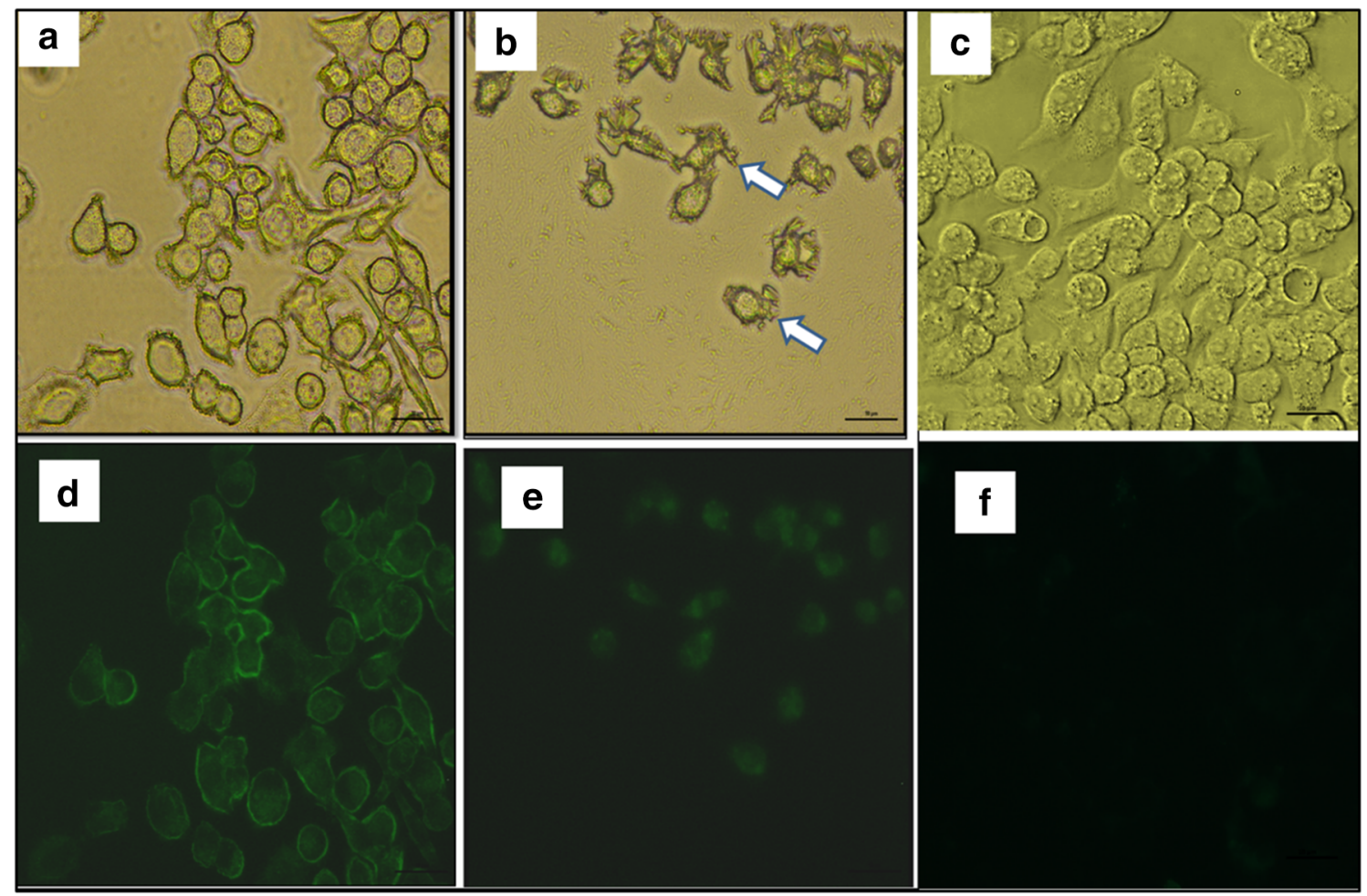

Fig. 8 Study of invasion inhibition ability of Sal- $06 \mathrm{mAb}$ in vitro on A549 epithelial cell line by phase contrast and fluorescent imaging. Panel a) Phase contrast image of epithelial cells incubated with Salmonella bacteria and Sal-06mAb. b) Phase contrast imaging of epithelial cells incubated with Salmonella bacteria alone (arrow mark shows the damaged cells).

c) Phase contrast imaging of epithelial cells alone. d) Fluorescent imaging of epithelial cells incubated with Salmonella bacteria and Sal-06mAb. e) Fluorescence imaging of epithelial cells incubated with Salmonella bacteria alone. f) Fluorescence imaging of epithelial cells alone 


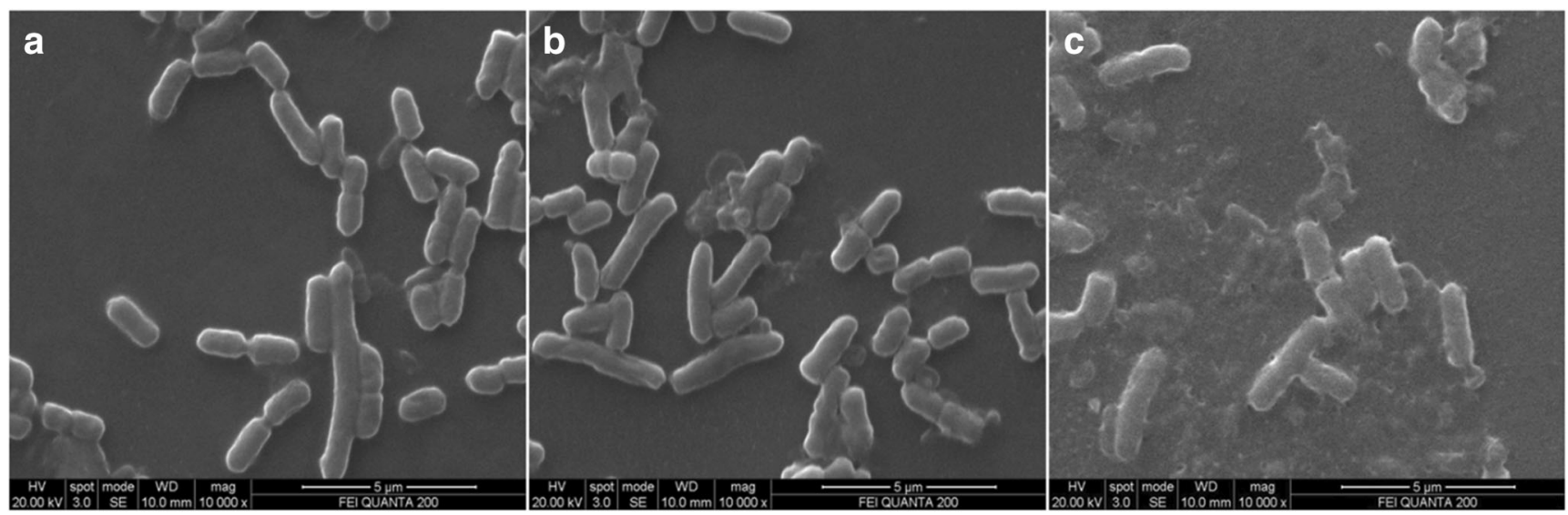

Fig. 9 Study of the effect of Sal-06mAb on morphology of $S$. typhimurium by a scanning electron microscope. a) Salmonella bacteria without mAb incubation (control). b) Salmonella cells incubated with Sal-06mAb for 1 h. c) Salmonella cells incubated with Sal-06mAb for 2 h

outer membrane proteins of typhimurium and enteritidis serovars (Tennant et al. 2016). Though the live attenuated vaccines are able to confer cross protection, the risk of virulence restoration in immune-compromised individuals is limiting their use (Haesebrouck et al. 2004). This led to focus on developing novel and alternative antimicrobial therapies offering high specificity, improved safety, less toxicity, broad immunity, and cross-protective efficacy against broad Salmonella serovars. Passive immunization has been utilized successfully as a suitable alternative to conventional antibiotic therapy against several gastrointestinal pathogens such as Salmonella, Campylobacter, Escherichia coli, and rotavirus (Esmailnejad et al. 2019; Rahimi et al. 2007). Antibodies exert their antimicrobial activity through binding and blocking the pathogen entry, neutralization, inhibiting growth, replication and dissemination, and membrane damage (Peddayelachagiri et al. 2014; Kovacs-Nolan and Mine 2004; Esmailnejad et al. 2019). Monoclonal antibodies have found their way in immunodiagnostics, pathogen identification, prevention, and therapeutic applications. Administration of monoclonal antibodies raised against conserved antigens of Enterobacteriaceae members might confer a neutralizing effect by antibodydependent cellular cytotoxicity (ADCC) effect.

Several earlier studies have explored the possibility of immunotherapy utilizing cross-reactive monoclonal antibodies against broad range of Enterobacteriaceae pathogens. A murine monoclonal antibody (WN1 222-5) capable of binding to LPS of E. coli and Salmonella has shown in vitro and in vivo cross-protective activity against LPS-induced lethality in mouse model (Di Padova et al., 1993). In another study, two monoclonal antibodies ST-1 and 10-5-6 directed against the Opolysaccharide of $S$. typhimurium LPS provided significant protection against the lethal challenge with homologous S. typhimurium strains (SR-11 and LT-2) in the $\mathrm{C} 3 \mathrm{H} / \mathrm{HeN}$ mice (Colwell et al., 1984). Michetti et al. (1992) reported the protective efficacy of a secretory IgA challenge by an invasive S. typhimurium by immune exclusion at the mucosal surface.
In a similar study, permanent secretion of mucosal $\operatorname{IgA}(\mathrm{mAb}$ 177E6) directed specifically against O:9 antigen into the respiratory tract through a backpack tumor model protected $50 \%$ of animals challenged with high dose of $S$. enteritidis strain through intranasal route (Iankov et al., 2004). Our work is in agreement with the above studies wherein a cross-reactive, surface protein targeted monoclonal antibody can neutralize the pathogen, thereby blocking its entry into the cells. Sal-06 monoclonal antibody was reactive to several species of Salmonella on dot ELISA and western blot analysis. Since several members of the family Enterobacteriaceae are closely related in structure, composition, and virulence mechanisms, we tested the cross-reactivity of Sal-06 monoclonal antibody on other members of genus such as Klebsiella, Proteus, Escherichia, and Enterobacter. The monoclonal body showed strong cross-reactivity with $K$. pneumonia, $P$. vulgaris, and $E$. coli indicating shared epitopes among these organisms. These cross-reactive pathogens are also of great clinical significance. Western blot analysis revealed the size similarity of cross-reactive antigen among the tested pathogens with that of Salmonella members. Antigen reactive to the Sal-06mAb was assumed to be of proteinaceous in nature and not a lipopolysaccharide (LPS) based on the distinct banding pattern of reactivity as opposed to ladder-like formation usually associated with LPS (Peddayelachagiri et al. 2014). Antibodies directed against bacterial surface components might prevent pathogen from establishing infection by blocking their binding sites, adhesion, and invasion into host cells. This effect is reflected in vitro on the rate of growth and survival of the bacteria. We observed that under in vitro conditions, the Sal- $06 \mathrm{mAb}$ inhibited the growth of actively dividing Salmonella bacteria for more than $4 \mathrm{~h}$ at $60 \mu \mathrm{g}$ quantity. We assume that such effect under in vivo conditions would be sufficient to induce opsonization and pathogen neutralization. This hypothesis needs to be studied in vivo in suitable animal model. In Sal$06 \mathrm{mAb}$, the $\mathrm{mAbs}$ bound to the pathogen surface and blocked their invasion into the A549 epithelial cell line. Adhesion of 
bacteria to the cell surface is the primary step in the establishment of infection. Prevention of bacterial invasion is promising in prevention of establishment of pathogenesis (Peddayelachagiri et al. 2014). Further, Sal-06 being an IgG1 subclass of $\mathrm{mAb}$ might display potent neutralization and phagocytic killing ability in vivo. SEM studies further complemented our assumptions of the surface location of antigen specific to Sal-06. In electron micrographs, it was clearly evident that $\mathrm{mAb}$ bound to surface epitopes and induced osmotic lysis of the bacterial cells which demonstrate its partial bacteriostatic action.

In conclusion, our work resulted in development of Sal$06 \mathrm{mAb}$ broadly reactive to few members of the family Enterobacteriaceae and demonstrated bacteriostatic properties against Salmonella species under in vitro conditions. The Sal-06mAb demonstrated broadly cross-reactive, bacteriostatic, and invasion inhibitory properties. Due to the shared epitopes among many pathogenic members of Enterobacteriaceae, the Sal-06mAb could be explored as a valuable therapeutic tool. However, additional and thorough in vivo preclinical and clinical validations need to be performed to realize this antibody for therapy. Approaches such as recombinant single-chain variable fragment (SCFV) antibodies and humanization strategies may also be explored. Further, the identity of antigen and epitope binding to Sal$06 \mathrm{mAb}$ also needs to be identified.

Acknowledgements The authors thank the Director, Defence Food Research Laboratory (DFRL), Mysore, and Head of Microbiology Division, DFRL, Mysore, for their support and encouragement during the study period. Shivakiran S. Makam thanks the Department of Science and Technology (DST), Government of India, for awarding Early Career Research (ECR) project (ECR/2016/000685). Prakash N. Reddy thanks the INSPIRE division of the Department of Science and Technology, Government of India, for providing INSPIRE faculty award and research grant (DST/INSPIRE/04/2017/000565). Rohini Krishna Kota thanks the Council of Scientific and Industrial Research (CSIR), Government of India, for awarding the Senior Research Fellowship (SRF) (09/1253(0002)/2019-EMR-I). The authors thank Mr. Joseph Anthuvan Allen from Bharathiar University - DRDO Centre for Life Sciences, Coimbatore, India, for helping with SEM analysis.

Funding information This study was funded by the Department of Science and Technology (DST), Government of India, under Early Career Research (ECR) scheme (ECR/2016/000685); INSPIRE division of Department of Science and Technology, Government of India (DST/ INSPIRE/04/2017/000565); and Council of Scientific and Industrial Research (CSIR), Government of India (09/1253(0002)/2019-EMR-I).

\section{Compliance with ethical standards}

Ethical approval All applicable international, national, and/or institutional guidelines for the care and use of animals were followed. All the animal experiments were conducted as per Institutional Animal Ethics Committee guidelines.

Conflict of interest The authors declare that they have no conflict of interest.

\section{References}

Abadi AH, Mahdavi M, Khaledi A, Esmaeili SA, Esmaeili D, Sahebkar A (2018) Study of serum bactericidal and splenic activity of TotalOMP-CagA combination from Brucella abortus and Helicobacter pylori in BALB/c mouse model. Microb Pathog 121:100-105

Babu L, Uppalapati SR, Sripathy MH, Reddy PN (2017) Evaluation of recombinant multi-epitope outer membrane protein-based Klebsiella pneumoniae subunit vaccine in mouse model. Front Microbiol 8:1805

Colwell DE, Michalek SM, Briles DE, Jirillo E, McGhee JR (1984) Monoclonal antibodies to Salmonella lipopolysaccharide: anti-Opolysaccharide antibodies protect $\mathrm{C} 3 \mathrm{H}$ mice against challenge with virulent Salmonella typhimurium. J Immunol 133(2):950-957

Di Febo T, Schirone M, Visciano P, Portanti O, Armillotta G, Persiani T, Di Giannatale E, Tittarelli M, Luciani M (2019) Development of a capture ELISA for rapid detection of Salmonella enterica in food samples. Food Anal Methods 12(2):322-330. https://doi.org/10. 1007/s12161-018-1363-2

Di Padova FE, Brade H, Barclay GR, Poxton IR, Liehl E, Schuetze E, McClelland DB (1993) A broadly cross-protective monoclonal antibody binding to Escherichia coli and Salmonella lipopolysaccharides. Infect Immun 61(9):3863-3872

Ebanks RO, Goguen M, McKinnon S, Pinto DM, Ross NW (2005) Identification of the major outer membrane proteins of Aeromonas salmonicida. Dis Aquat Org 68(1):29-38. https://doi.org/10.3354/ dao068029

Eng SK, Pusparajah P, Ab Mutalib NS, Ser HL, Chan K, Lee LH (2015) Salmonella: a review on pathogenesis, epidemiology and antibiotic resistance. Front Life Sci 8(3):284-293. https://doi.org/10.1080/ 21553769.2015.1051243

Esmailnejad A, Abdi-Hachesoo B, Nasab EH, Shakoori M (2019) Production, purification, and evaluation of quail immunoglobulin Y against Salmonella typhimurium and Salmonella enteritidis. Mol Immunol 107:79-83. https://doi.org/10.1016/j.molimm.2019.01. 012

Ghatak S, Agrawal RK, Bhilegaonkar KN (2003) Detection of Aeromonas spp. from milk and meat by enzyme-linked immunosorbent assay. J Vet Public Health 1(1):17-24

Haesebrouck F, Pasmans F, Chiers K, Maes D, Ducatelle R, Decostere A (2004) Efficacy of vaccines against bacterial diseases in swine: what can we expect? Vet Microbiol 100(3-4):255-268. https://doi.org/10. 1016/j.vetmic.2004.03.002

Iankov ID, Petrov DP, Mladenov IV, Haralambieva IH, Kalev OK, Balabanova MS, Mitov IG (2004) Protective efficacy of IgA monoclonal antibodies to $\mathrm{O}$ and $\mathrm{H}$ antigens in a mouse model of intranasal challenge with Salmonella enterica serotype Enteritidis. Microb Infect 6(10):901-910

Isibasi A, Ortiz V, Vargas M, Paniagua J, Gonzalez C, Moreno J, Kumate J (1988) Protection against Salmonella typhi infection in mice after immunization with outer membrane proteins isolated from Salmonella typhi 9, 12, d, Vi. Infect Immun 56(11):2953-2959

Khushiramani R, Girisha SK, Bhowmick PP, Karunasagar I, Karunasagar I (2008) Prevalence of different outer membrane proteins in isolates of Aeromonas species. World J Microbiol Biotechnol 24(10):22632268. https://doi.org/10.1007/s11274-008-9740-4

Kovacs-Nolan J, Mine Y (2004) Passive immunization through avian egg antibodies. Food Biotechnol 18(1):39-62. https://doi.org/10.1081/ FBT-120030384

Laemmli UK (1970) Cleavage of structural proteins during the assembly of the head of bacteriophage T4. Nature 227(5259):680

Lamas M, Miranda JM, Regal P, Vásquez B, Franco CM, Cepeda A (2018) A comprehensive review of non-enterica subspecies of Salmonella enterica. Microbiol Res 206:60-73. https://doi.org/10. 1016/j.micres.2017.09.010 
Li C, Ye Z, Wen L, Chen R, Tian L, Zhao F, Pan J (2014) Identification of a novel vaccine candidate by immunogenic screening of Vibrio parahaemolyticus outer membrane proteins. Vaccine 32(46):61156121. https://doi.org/10.1016/j.vaccine.2014.08.077

Li G, Huang Y, Duan M, Xing K, You X, Zhou H, Liu Y, Liu C, Liu D, Lai W (2019) Biosensing multiplexer based on immunochromatographic assay for rapid and high-throughput classification of Salmonella serogroups. Sensors Actuators B Chem 282:317-321. https://doi.org/10.1016/j.snb.2018.11.081

Lin J, Huang S, Zhang Q (2002) Outer membrane proteins: key players for bacterial adaptation in host niches. Microbes Infect 4(3):325331. https://doi.org/10.1016/S1286-4579(02)01545-9

Liu Q, Tan K, Yuan J, Song K, Li R, Huang X, Liu Q (2018) Flagellindeficient outer membrane vesicles as adjuvant induce crossprotection of Salmonella typhimurium outer membrane proteins against infection by heterologous Salmonella serotypes. Int J Med Microbiol 308(7):796-802. https://doi.org/10.1016/j.ijmm.2018.06. 001

Meenakshi M, Bakshi CS, Butchaiah G, Bansal MP, Siddiqui MZ, Singh VP (1999) Adjuvanted outer membrane protein vaccine protects poultry against infection with Salmonella enteritidis. Vet Res Commun 23(2):81-90. https://doi.org/10.1023/A:1006250301254

Michetti P, Mahan MJ, Slauch JM, Mekalanos JJ, Neutra MR (1992) Monoclonal secretory immunoglobulin A protects mice against oral challenge with the invasive pathogen Salmonella typhimurium. Infect Immun 60(5):1786-1792

Peddayelachagiri BV, Paul S, Makam SS, Urs RM, Kingston JJ, Tuteja U, Sripathy MH, Batra HV (2014) Functional characterization and evaluation of in vitro protective efficacy of murine monoclonal antibodies BURK24 and BURK37 against Burkholderia pseudomallei. PLoS One 9(3):e90930. https://doi.org/10.1371/ journal.pone.0090930

Rahimi S, Shiraz ZM, Salehi TZ, Torshizi MAK, Grimes JL (2007) Prevention of Salmonella infection in poultry by specific eggderived antibody. Int J Poult Sci 6(4):230-235

Stanaway JD, Parisi A, Sarkar K, Blacker BF, Reiner RC, Hay SI, Nixon MR, Dolecek C, James SL, Mokdad AH, Abebe G, Ahmadian E, Alahdab F, Alemnew BTT, Alipour V, Allah Bakeshei F, Animut MD, Ansari F, Arabloo J, Asfaw ET, Bagherzadeh M, Bassat Q, Belayneh YMM, Carvalho F, Daryani A, Demeke FM, Demis ABB, Dubey M, Duken EE, Dunachie SJ, Eftekhari A, Fernandes E, Fouladi Fard R, Gedefaw GA, Geta B, Gibney KB, Hasanzadeh A, Hoang CL, Kasaeian A, Khater A, Kidanemariam ZT, Lakew AM, Malekzadeh R, Melese A, Mengistu DT, Mestrovic T, Miazgowski B, Mohammad KA, Mohammadian M, Mohammadian-Hafshejani A, Nguyen CT, Nguyen LH, Nguyen SH, Nirayo YL, Olagunju AT, Olagunju TO, Pourjafar H, Qorbani M, Rabiee M, Rabiee N, Rafay A, Rezapour A, Samy AM, Sepanlou SG, Shaikh MA, Sharif M, Shigematsu M, Tessema B, Tran BX, Ullah I, Yimer EM, Zaidi Z, Murray CJL, Crump JA. (2019) The global burden of non-typhoidal Salmonella invasive disease: a systematic analysis for the Global Burden of Disease Study 2017. Lancet Infect Dis 19(12): 1312-1324

Publisher's note Springer Nature remains neutral with regard to jurisdictional claims in published maps and institutional affiliations. 